\title{
EL VALOR EMANCIPATORIO DE LO PROPIO EN LA OBRA DE GUADARRAMA
}

\author{
Yodenis Guirola Valdés* \\ Universidad de Barcelona
}

DOI: http://dx.doi.org/10.14718/CulturaLatinoam.2020.31.1.14

\section{La proximidad emblemática de Guadarrama González}

"Honor a quien honor merece", fueron palabras del maestro, del gran cubano universal que encarnó José Martí, prócer de América, en la segunda mitad del siglo XIX. Y es honor, precisamente, el que se ha de rendir a Guadarrama González ante la consagración de la obra de toda una vida, un honor que, al honrar, ciertamente honra.

$\mathrm{Y}$ es que para quienes nos formamos en la Universidad Central de Las Villas en Cuba -la alta casa de estudios a la que por excelencia ha consagrado su vida y de la que es hoy insigne profesor de mérito-, sabemos por experiencia propia que ya en aquellos difíciles años noventa del siglo pasado, años de redefiniciones y reajustes determinantes, Guadarrama encarnaba la figura del profesor prominente y a la vez cercano, el intelectual consecuente y orgánico, situado desde la tesitura de lo propio y alejado de las retóricas poco convincentes de la ortodoxia más retrógrada del DIAMAT, por entonces remanente.

\footnotetext{
* Ph.D. en Filosofía por la Universidad de Barcelona, donde obtuvo también el Diploma de Estudios Avanzados en Filosofía, DEA en Ética, Política y Racionalidad en la Sociedad Global.
}

Referencia: Guirola Valdés, Y. (2020). El valor emancipatorio de lo propio en la obra de Guadarrama. Cultura Latinoamericana, 31 (1), pp. 343-375. DOI: http://dx.doi. org/10.14718/CulturaLatinoam.2020.31.1.14 
En aquel contexto ciertos discursos cerrados eran palpablemente presentados como incuestionable verdad objetiva, científica y única. Fueron años difíciles en los que recurrentemente se invocaba a las barricadas intelectuales y al atrincheramiento argumental en virtud de la debilidad y no de la fortaleza de los argumentos propios como antídoto a la desidia de la izquierda tras la caída del campo socialista. Sin embargo, Guadarrama, desmarcado de tales remanentes, apostó siempre por una construcción del discurso propio imbuido en la consideración de valor de lo otro, en sintonía sin duda alguna con aquel precepto que en su momento apuntase José Vasconcelos en cuanto a que la liberación no se alcanza negando lo extraño, sino construyendo lo propio.

El nombre de Pablo Guadarrama resonó siempre de un modo especial en alumnos y profesores, encarnaba el espíritu de la apuesta convencida y reconocida a todos los niveles, la constatación de una obra docente e investigativa imprescindible como sello de lo propio desde las aulas de la Universidad Central "Marta Abreu" de las Villas. Como referente intelectual y docente, su imagen se hizo emblemática y se conjugó siempre con una especie de espectro de paso firme por cualquiera de los contornos del campus universitario, entre una facultad y otra, entre un recinto y otro, atizando ideas a su andar y optimizando maestramente los sesenta segundos de cada minuto. Y así iba, casi siempre cargado de dos maletas atestadas de libros, dos y no una, alternando la más pesada colgada de los hombros con la otra bien asida a punta de puño, con una mano siempre libre para estrechar al colega o al estudiante. Un Pablo, sin lugar a duda, emblemático de aquellos pasillos villaclareños, de aquellos predios que transcendieron la propia universidad.

Pablo marcó un referente para quienes hallamos en su obra y en su trayectoria un itinerario que arrojó siempre luz a las cuestiones propias, un sendero por donde habría de encaminarse la apuesta por un marxismo sin calco ni copia, de un latinoamericanismo conjugado con los valores y con el legado del pensamiento y de la historia cubana toda, en la que se insertaba el legado de lo universal y a lo universal se revelaba. Una obra la suya, que trascendía y trasciende el marco pautado por la mera academia. Incluso para quienes directamente no le conocían o no le escucharon por entonces, y para quienes estaban lejos profesionalmente del ámbito de las ciencias sociales, el nombre de Pablo Guadarrama se alzó como referente indiscutible del intelectual desde Cuba y en Cuba, del éxito académico y de la posibilidad de, efectivamente, tratar cuestiones universales, sociales, políticas, humanistas, antropológicas, existenciales, etc., de un modo contundente 
y a la vez atractivo a los ojos de la cotidianidad cubana. Una realidad que se le reveló siempre cercana por cuanto de propio había en ello. $\mathrm{Y}$ en tal orden, a quienes por entonces estuvimos en las aulas de la Universidad Central, no pocas veces se nos preguntó fuera de aquel marco quién era Guadarrama, si le conocíamos, si le habíamos escuchado, quién y cómo era aquel filósofo villaclareño con repercusión internacional que apostaba por una filosofía en clave latinoamericana y latinoamericanista.

Toda una merecida notoriedad que trascendió los predios meramente docentes o correspondientes a las ciencias sociales estricto sensu, y que encarnó con toda seguridad justamente el espíritu de lo que Enrique José Varona diría del "tipo cabal del hombre de letras, por vocación y dedicación”, una referencia que el propio Pablo tendría en cuenta y asumiría como valor en su trabajo sobre el pensador nacido en Santa María de Puerto Príncipe en 1849, justo un siglo antes que él. Y es que la obra de Guadarrama ha estado precisa y justamente en sintonía con aquel precepto del universal autor camagüeyano: determinada por "ese amor y el concepto de la dignidad profesional que inspira", la cual "nos da estudios completos desde el punto de vista de la información, sinceros, y cuando el caso lo demanda, vivificados por el calor de la emoción hondamente sentida" (Vitier, 1949, p. 86). Eso diría Varona en los albores del siglo XX, en 1904, pero, sin lugar a duda, podría haber dicho lo mismo de haber conocido la obra de Guadarrama y de haber podido escribir ciento diez años después en estas fechas y para este homenaje algo así como "Leyendo a Guadarrama".

Un Pablo desde su más completa accesibilidad humana, siempre lejos de cualquier signo de ostracismo intelectual, siendo como de hecho es, convencido y abierto, dialogante y brillantemente coherente en su discurso. Un discurso que articula lo propio con lo universal, lo cubano y lo latinoamericano con lo mejor de las tradiciones filosóficas e intelectuales heredadas desde los tiempos clásicos, pasando por el inmenso baluarte filosófico y cultural del occidente moderno y contemporáneo. En tal espectro histórico, Pablo efectivamente, ha hallado el lugar de la tradición marxista en su conjunto, así como su aporte indiscutible al entendimiento y a la práctica de los pueblos, incluida la de la compleja realidad latinoamericana y, en especial, de la cubana.

Parafraseando a otro villaclareño universal, al guajiro ilustrado que fue Samuel Feijóo (2007), y salido de sus versos contenidos en El pensador silvestre - toda una oportuna sugerencia desde su título mismo-, pudiera decirse que "ese caminito / entre las yerbas / mis pies lo hicieron: / sin los pies caminantes, / no existiera" (p. 105). Y es 
que el sendero que Guadarrama ha transitado ha sido precisamente abierto a fuerza de su propio paso sobre la yerba donde antes de sí mismo no había tal caminito, o al menos no en la dimensión en la que él se ha encargado de perfilar de modo impetuoso. A efecto de ello ha dejado su huella y a fuerza de su paso ha construido su propio camino. "Caminante no hay camino", pareciera resonar en todo su historial escrito, y haber sido fiel toda su vida a aquel verso de Antonio Machado y haberse hecho con toda justicia su propio "camino al andar".

Desde su temprana decisión de dedicarle su tesis doctoral al pensamiento de Enrique José Varona y no a Kant o a Hegel, nada más y nada menos que en la mismísima Universidad de Leipzig, transitando por el descubrir del valioso arsenal contenido en la obra de los pensadores latinoamericanos tradicionalmente ignorados en los programas de filosofía que han regido tradicionalmente el mundo, sobre todo el occidental, Guadarrama ha reivindicado el valor de lo propio como universalidad.

En el prólogo a las Valoraciones sobre el pensamiento cubano y latinoamericano (1985), de Guadarrama, el casi octogenario Gaspar Jorge García Galló1, a sí mismo definido como "viejo maestro cubano y comunista (...) interesado por la educación y la investigación en la filosofía", confesaría sentirse feliz y seguro del relevo generacional que ya por entonces encarnaba Guadarrama, "dedicado a investigar, no solo el pensamiento cubano sino de toda nuestra América con un enfoque historiográfico" dentro de la tradición marxista desde el rótulo del "marxismo-leninismo". Lo cual habría de poner a Cuba, a decir de Galló, "también en un lugar cimero de la investigación filosófica"2.

1. El mencionado pedagogo cubano nació en Quivicán, en la provincia de La Habana, el 6 de enero de 1906. Habiendo realizado estudios en filosofía y letras en La Habana y doctorándose en pedagogía, ejerció como profesor de la Escuela Normal de Santa Clara en los años treinta del siglo veinte, y obtuvo la cátedra de lengua y literatura griegas de la Escuela de Filosofía y Letras de la Universidad Central de Las Villas en 1952. Alternó sus labores académicas con una intensa actividad sindical y revolucionaria que trascendió el marco de los predios universitarios y tuvo resonancia en los sectores más humildes del campesinado y la clase obrera cubana. De modo que, al triunfo de la Revolución, en la referida alta casa de estudios del centro de la isla, fue elegido decano de la Facultad de Filosofía y Letras. En esta propia universidad, y tras toda una vida de docencia e investigación, es hoy Guadarrama González profesor de mérito. Tuvo entonces razón Galló.

2. Valdría apuntar en cuanto a ello que en el ámbito de la filosofía en Cuba se habían dado importantes avances y momentos de verdadero auge con cierta pluralidad filosófica. Guadarrama vendría a tributar al rescate de tales momentos y autores anteriores, y se inscribiría además en un nuevo periodo del desarrollo de la filosofía en Cuba identificado con la tradición marxista, y muy en concreto tras el rótulo del marxismo-leninismo al cual tributaría, pero desde el marco del cual apostaría por lo propio, encarnando una postura heterodoxa y crítica. El propio Guadarrama reconocería en múltiples de sus trabajos el gran desarrollo alcanzado por la filosofía en Cuba ya a mediados de la década de los cincuenta del siglo XX, de hecho, sus valoraciones sobre Varona constatan tal presunción. Y no solo en Cuba, sino en toda América Latina.

"Es cierto que la filosofía en América Latina —diría Guadarrama (2004) — alcanzó a mediados del siglo XX un indiscutible alto nivel de profesionalidad y riqueza, pero sus referentes no fueron solo los del pensamiento europeo". 
Y aseguraría, además, el viejo maestro cubano que "Ya podemos, los muy pocos que intentamos hacerlo, entonces, morir tranquilos. ¡Está asegurado el relevo!” (p. VI).

Y en efecto, bien vislumbró García Galló el relevo generacional que Guadarrama representaría para los estudios de pensamiento cubano y latinoamericano desde una perspectiva marxista y humanista, tanto en Cuba como en América Latina. Desde entonces, a la fecha, la producción de Guadarrama ha incluido una extensa lista de publicaciones en la que los ejes centrales han girado en torno al pensamiento filosófico latinoamericano, positivismo y antipositivismo, marxismo y antimarxismo, así como el humanismo en América Latina, sin perder de vista cuestiones culturales, antropológicas, filosóficas y sociopolíticas de actualidad con relación a sus temáticas tratadas. Por demás, no se ha limitado a la tarea de cultivar numerosas publicaciones, sino que ha encarnado la piedra angular de la articulación y desarrollo de los estudios sobre pensamiento latinoamericano desde el centro de la isla de Cuba. En tal sentido, habiendo fundado la Cátedra de Pensamiento Latinoamericano 'Enrique José Varona' de la Universidad Central "Marta Abreu" de Las Villas", y en el marco de trabajo del Grupo de Estudios de Pensamiento Latinoamericano impulsado desde la referida Cátedra, ha extendiendo su labor y conexión, a lo largo de todo el país y de América Latina, mediante la articulación del trabajo de múltiples autores en Cuba y fuera de Cuba, y con el impulso a programas de formación de grado y postgrado, así como de especialización, maestrías y doctorados en este campo de estudios. Entre otros muchos proyectos desarrollados, valga destacar durante la última década su labor como Coordinador General del Proyecto Internacional auspiciado por la UNESCO, "El pensamiento latinoamericano del siglo XX ante la condición humana” (2001-2013), que integró una importante red de trabajo de investigadores de múltiples latitudes a un lado y otro del Atlántico, con muy relevantes resultados en el rescate y reivindicación del pensamiento latinoamericano.

No es casual que la universalidad de autores emblemáticos como el gran León Tolstoi haya estado inscrita precisamente en la magistralidad con que contó la particularidad de lo propio. Como tampoco es casual que el insigne pensador mendocino Arturo Andrés Roig (2002) en sus "respuestas a la crisis moral de nuestro tiempo" y como parte de su apuesta por la "moralidad de la protesta", destacase al gran escritor ruso entre otros autores de talla universal (p. 221). Y es que Tolstoi sabiamente apelaría al valor de lo propio como universalidad. "Pinta tu aldea y serás universal", sentenciaría, así como es por tal 
motivo que, precisamente, Guadarrama puede ser considerado, y de hecho es, un autor universal. Durante su extensa y prolifera carrera profesional, Guadarrama ha develado al mundo la multiplicidad de los colores de su aldea en el sentido tolstoyano, de su Patria Grande que es Nuestra América, así dicho. Y lo ha hecho desde los senderos del humanismo latinoamericano en el cual se inscribe y al cual tributa de un modo significativo.

\section{Del humanismo de Pablo Guadarrama}

Poco antes de morir, el insigne pensador mexicano Leopoldo Zea (2003) dedicaría un certero y entrañable artículo sobre el humanismo del pensador cubano, y así precisamente lo titularía: "El humanismo de Guadarrama”. En aquellas líneas publicadas en el Excélsior de México el domingo 30 de noviembre de 2003, Zea quiso "hacer patente lo que representa Guadarrama" (p. 2) en el contexto latinoamericano, heredero del humanismo de José Martí en conjunción con la herencia marxista. Y es que la obra de Guadarrama, como su persona misma, no pasarían inadvertidas para el trascendental filósofo mexicano; y en efecto, parte del impulso y del espacio que en sus inicios tendría Guadarrama como expositor en múltiples foros internacionales, especialmente en México, vendría del propio interés del mismo Zea en dar visibilidad y propiciar el diálogo con el trabajo de Guadarrama.

En una línea similar, en cuanto a la definición humanista de la obra del autor villaclareño se refiere, pudiera asumirse sin mayor dificultad epistémica el rótulo que esbozase Enrique Dussel al referirse al trabajo de Guadarrama en términos de "marxismo humanista cubano". Tal y como apunta Dussel (2003), es un humanismo que emerge como parte de situaciones concretas, sean estas acontecidas en el marco de la historia propia, especialmente de la historia cubana y latinoamericana, y como parte de un loable y meritorio esfuerzo ${ }^{3}$ que ha caracterizado la continuidad de la obra de Guadarrama.

Volviendo al mencionado artículo de Leopoldo Zea, el autor mexicano recordaría con manifiesto cariño la anécdota de un viaje en el que ambos coincidirían en el trayecto hasta los confines de Osaka en

3. Refiriéndose a Guadarrama, Dussel (2003) apuntaría en la referida obra que "they emerged from concrete situations, such as Cuban Marxist humanism" (p. 33). Y en igual sentido, y más allá de su crítica, se referiría a ello como "The very worthy analysis by the Cuban team" (Nota 130, p. 142). 
Japón, en el marco del encuentro de la Federación Internacional de Estudios de América Latina y el Caribe. Toda una metáfora de lo que estos dos consagrados venidos de las entrañas sentidas de América llevarían hasta allí, hasta la desembocadura de otro coloso natural caracterizado precisamente por aunar en su trayecto, el Yodogawa, la mayor cantidad de afluentes en aquella región insular del Este de Asia. Una especie de metáfora del crisol de herencias que convergen en el pensar, tanto de Zea como de Guadarrama, para dar cada uno de sí lo mejor en términos de pensamiento latinoamericano.

Fue en ese viaje en el que Guadarrama y Zea, a juzgar por lo que el propio Zea reseña, dialogaron sobre las razones de la herencia marxista en Cuba, de los derroteros por los que transitó la asunción de una ideología marxista a nivel de Estado en la isla, de algunos determinantes porqués, de ciertas sintonías y de ciertas desavenencias en cuanto al sentido del marxismo-leninismo en la mayor de las Antillas, su conjugación con el ideal humanista martiano y la condicionante fáctica en el marco de la complejidad geopolítica de aquellos años iniciales de la década de los sesenta, la Guerra Fría, la estrategia Made in USA, los contrapesos de los entonces dos bloques, y la impronta de todo ello en la apuesta ideológica de Fidel Castro y del ordenamiento sociopolítico que con ello se inauguraba de modo inédito en la isla y en América Latina. Zea y Guadarrama dialogaron sobre tales cuestiones en ese viaje, tal y como lo habían hecho sobre positivismo y pensamiento latinoamericano otras tantas veces anteriores en La Habana y en México.

Fue para el pensador mexicano una constatación que le llevó a escribir que había encontrado siempre en Guadarrama "a una persona muy amiga", quien le explicaba su enfoque y que comprendía el suyo, también en cuanto al marxismo-leninismo se refería. Y en cuanto a esto último, valga además la referencia que en otro de sus trabajos el propio Guadarrama diese con relación a la perspectiva que en el marco de otros pensadores asumiese Zea respecto al argumento marxista: "La actitud de Zea ha sido mucho más cautelosa en relación con el marxismo, pero no menos reconocedora de los aportes teóricos de esta filosofía, sin compartir todas sus tesis ni sus consecuencias sociopolíticas" (Guadarrama, 1993, p. 180).

De modo que, en el diálogo entre los dos pensadores, por sobre todas las cosas, siempre existió un espíritu de interés mutuo por los argumentos del otro, asumiendo el sentido de lo latinoamericano como valor común: 
Sé de la preocupación humanista de Guadarrama. Sé de su preocupación por conocer e integrar en su conciencia las diversas expresiones de lo humano a lo largo de América Latina. Es la misma preocupación que siento al contar con el privilegio de haber nacido en esta región de la tierra (...). Contando, igualmente, con el privilegio que el destino me ha dado de llenar esta preocupación personal con el conocimiento a plenitud de la región, mi región, a la que José Martí llamó "Nuestra América”. (Zea, p. 2)

Hay en ello, sin duda alguna, una sintonía mayor, un espíritu de lo propio que encuentra en ambos pensadores un sendero que tributa al mismo obrar latinoamericanista, "la misma preocupación" y el mismo "privilegio" afincado desde lo que ha dado en llamarse nuestroamericano. Y es que Zea dialogaría resueltamente con Guadarrama sobre cuestiones disímiles concernientes a la América Latina en su complejidad y en su diversidad.

De ambas herencias, tal y como Zea advirtiera, Guadarrama "viene actuando a lo largo de su fructífera vida, tratando de conciliar lo que resulte conciliable, esto es, un instrumento de conocimiento con una postura de carácter moral". Y es que para Guadarrama la apuesta por el método dialéctico-materialista y su tradición en conjunción con el humanismo latinoamericano no se reduce a la mera deriva epistémica, sino que hay en ello una dimensión que encarna una cierta ética de lo concreto en tanto parte de lo concreto y desde lo concreto y su necesidad histórica se articula.

De modo que el bumanismo guadarramiano -por si se nos permitiese el término- puede definirse como la articulación crítica del método dialéctico-materialista y de la herencia humanista latinoamericana, operando desde la manifiesta intención del rescate de lo propio como valor emancipatorio. Un valor que se conjuga en su apuesta por el humanismo como contraparte a la alienación en cualquiera de sus formas. Tal perspectiva es inseparable de su compromiso práctico y su apuesta es clara por un orden social más allá de los fundamentos de la explotación capitalista y de los dogmatismos amparados por cierta ortodoxia acrítica de la cual el propio Guadarrama contundentemente se desmarca desde muy temprano.

Así, pues, su pensamiento opera en dos ámbitos fundamentales: los del rescate del pensamiento latinoamericano como parte de su apuesta por el valor de lo propio y su contribución como pensador en clave auténtica ${ }^{4}$ a las acuciantes problemáticas tanto de América

4. Valga aquí la propia noción de auténtico que Guadarrama maneja y a la que se hace referencia más adelante. 
Latina y Cuba como del mundo. El desarrollo de su concepción opera además desde una fuerte vocación pedagógica que precisamente halla en el humanismo latinoamericano sus fundamentos.

\section{Del impacto de la obra de toda una vida}

La obra de toda una vida se articula en Guadarrama entre la investigación tenaz y la docencia permanente, habiendo trascendido el espacio de las aulas cubanas. Su inmediata, cercana y siempre detallada respuesta ante la demanda del estudiante o del colega constatan que Guadarrama ha asumido siempre como propio el precepto que esbozase Enrique José Varona (1918) en cuanto al rol del pedagogo, un rol no delimitado al mero conocimiento:

Desde la escuela a la universidad la necesidad, el propósito y el deber de los profesores se concentran en formar hombres. Hombres que se sientan capaces de actuar frente a la naturaleza, para sacar de ella las utilidades que le permiten vivir y desarrollarse, que se sientan solidarios de sus coasociados, para concurrir con ellos a la generosa empresa de hacer mejor, más bella y noble la condición bumana”. (p. 37)

La implicación tanto pedagógica, como humanista y latinoamericanista de Guadarrama se inscribe en el curso de su vida desde muy tempranos momentos en los que formó parte de una generación de adolescentes y jóvenes que quijotesca y valerosamente asumieron el trascendente reto de contribuir en la erradicación del analfabetismo en Cuba en los inicios mismos de los años sesenta ${ }^{5}$. Allí se fraguó ya ese espíritu pedagógico que encontraría continuidad en sus estudios de profesor de enseñanza media superior en historia y geografía, una humilde y consagrada puerta de entrada al universo de lo profesional desde el Instituto Superior Pedagógico "Félix Varela", en 1967, institución que por entonces se encontraba en la que sería su casa para toda una vida, la Universidad Central de Las Villas. Se suman,

5. Que sean las palabras de Gaspar Jorge García Galló en su prólogo a Valoraciones sobre el pensamiento cubano y latinoamericano las que aludan a aquellos años iniciales de Guadarrama, quien, tal y como resaltase Galló, nacería en un hogar de trabajadores tabacaleros, un 10 de mayo de 1949, de modo que, al triunfar la Revolución Cubana tenía diez años y siendo todavía un niño se incorporaría a las Patrullas Juveniles y luego a la Asociación de Jóvenes Rebeldes, siendo uno de los jóvenes alfabetizadores que tributó a la erradicación del analfabetismo en la isla de Cuba (proclamada territorio libre de analfabetismo el 22 de diciembre de 1961). Hay, no cabe duda, un gran mérito histórico en ello. 
además, su complementación con los estudios de instructor de filosofía en la Universidad de La Habana, titulándose en 1968, su licenciatura en historia obtenida en 1976, su doctorado en filosofía en 1980 en la extinta RDA, así como su segundo doctorado en ciencias en 1995, otorgado en Cuba. Todo ello en el marco de una intensa labor pedagógica conjugada con la más estricta y tenaz labor investigativa de alto calado.

Ya desde antes de doctorase en Leipzig, y durante el conjunto de más de cuatro décadas dedicadas en exclusivo al estudio del pensamiento latinoamericano, Guadarrama ha constituido desde Cuba una referencia obligada en este campo al que ha dedicado prolíferamente su paso por este mundo. Desde muy temprano su obra, tanto pedagógica como investigativa, tuvo su impacto en el propio espacio académico cubano, y trascendió lo meramente nacional para situarse como referente de la filosofía que, desde Cuba y América Latina, se hacía ya hacia finales de la década de los ochenta del siglo XX. En tal sentido, valga hacer notar que, unido a todo el despliegue referencial registrado sobre su obra en múltiples espacios, tanto en Cuba como en América Latina, ya en aquellos primeros años su trabajo ganó visibilidad en contextos bien disímiles como el alemán (Gerstenberg, 1987, pp. 964-966), el ruso (Aladin y Cruz, 1988) o el de la propia academia norteamericana (Gracia,1988) con relación a los estudios de historia de las ideas que desde América Latina y Cuba se impulsaban por pensadores como él mismo.

Resultan particularmente relevantes de ese temprano impacto el interés generado por su tesis doctoral en lengua alemana y por sus artículos editados también en alemán en aquellos años iniciales, en los que José Ferrater Mora halló un motivo suficiente para su traducción a la lengua inglesa y su referencia como representativo de una joven generación que asumía de un modo intelectualmente comprometido el estudio del pensamiento latinoamericano. Unas referencias a su obra escrita que, como se ha dicho, se ha conjugado desde entonces con una intensa labor docente en múltiples escenarios a lo largo de toda América y Europa.

Desde entonces, a la fecha, se han prodigado las múltiples referencias a la obra de Guadarrama, así como la inclusión de su nombre como entrada en múltiples obras sobre el pensamiento latinoamericano, entrevistas y comentarios a sus trabajos. En suma, su obra "es toda una reivindicación del pensamiento latinoamericano desde una perspectiva humanista", tal y como diría Pedro Ribas (2012, p. 242). Y Guadarrama también, como recientemente apuntase Carlos Rojas 
Osorio (2009), "caracteriza la filosofía latinoamericana, por el humanismo, la búsqueda de la emancipación y la crítica antihegemónica" (p. 484).

Para justipreciar la relevancia y trascendencia de la activa apuesta de Guadarrama por la filosofía en clave latinoamericanista y cubana, valdría la pena destacar el impacto que la misma tuvo, tanto fuera como dentro de Cuba, en particular en los propios cubanos dedicados por entonces a los ámbitos de la filosofía. En tal sentido resulta sumamente ilustrativa la referencia que Enrique Ubieta (2003) hiciera a propósito del prólogo a José Martí y el Humanismo en América Latina:

Cuando en 1982 anunciaron en la Facultad de Filosofía de la Universidad Estatal de Kiev la inusual presencia de un conferencista invitado proveniente de Cuba, nosotros, estudiantes cubanos de quinto año, sonreíamos doblemente prejuiciados: primero, porque conocíamos a ciertos 'aspirantes' -aspiraban a ser, según una literal y mala traducción, 'candidatos a doctor' - que reunían muchos méritos personales, pero pocos estrictamente académicos; segundo, porque una formación eurocéntrica y teoricista nos hacía despreciar la tradición latinoamericana de pensamiento. El conferencista se nombraba Pablo Guadarrama, y no habló de Hegel, sino de Enrique José Varona. Un amigo y yo le tradujimos, con incredulidad, ante un auditorio sorprendido. (p. 11)

$\mathrm{Y}$ ha sido precisamente la superación del prejuicio etnocentrista uno de los elementos que ha marcado toda la obra de Guadarrama, haciendo visible el valor de lo propio en un redescubrir de la tradición latinoamericana desde claves históricamente ignoradas, menospreciadas o subestimadas incluso en los planos mismos de la propia academia latinoamericana y cubana. Una vuelta de página que tiene en Guadarrama uno de los pilares innegables de tal apuesta. Una apuesta consecuente con el precepto martiano de que "la universidad europea ha de ceder a la universidad americana", y de que "nuestra Grecia es preferible a la Grecia que no es nuestra". Cuestiones estas que nuestro autor villaclareño ha tenido siempre muy en cuenta, con lo cual es de entender que, en el marco de su trayectoria, tal incredulidad y sorpresa antes aludida se revirtieran en una reconsideración del valor de lo propio en términos de pensamiento filosófico latinoamericano:

Cuando los filósofos cubanos — continuaría diciendo Ubieta- (jóvenes y menos jóvenes, con las excepciones que fija la regla) andábamos de espaldas a la tradición latinoamericana y de cara a la teoría soviética —este- 
europea o eurooccidental —, (...) Pablo se empeñó en reconstruir, desde el marxismo, los hilos lógicos que nos unían al pasado. Hoy podemos disentir de sus argumentos o de su enfoque, pero mucho le debemos por habernos redescubierto un cuerpo histórico. Pablo no solo le tendió puentes críticos al pasado, sino que restituyó el diálogo con los colegas del continente. (p. 12)

Incluso más allá de la postura, crítica o no, que pueda asumirse ante la tradición marxista en América Latina, y en especial en Cuba, tanto para seguidores como para detractores, resulta innegable el papel de Guadarrama en la configuración de una línea de trabajo que tiene entre sus fundamentos el valor de lo propio y su rescate. Incluso convencidos y declarados detractores, ya no solo de la perspectiva del filósofo de la Universidad Central de Las Villas, sino del marxismo en sentido general ${ }^{6}$, irremediablemente reconocerían la trascendencia de la obra del autor villaclareño.

Así, desde la escisión del propio ámbito académico cubano con visibilidad en ediciones tradicionalmente contrarias al esquema que Guadarrama defiende, figuras como Alexis Jardines (2004), incluso en el marco de su denodada y visceral crítica a todo lo proveniente de la tradición marxista en la isla ${ }^{7}$, necesariamente reconocería que "Pablo Guadarrama es el profesor cubano que más ha hecho por la historia de las ideas en Cuba en el período revolucionario” (p. 92). Y más allá de no compartir la perspectiva del autor de Villa Clara, reconocería "su meritoria labor en este campo en el que es, sin duda, la máxima autoridad entre los marxistas de la Isla” (p. 92). Y también en una tesitura similar, y desde las páginas de la mencionada edición en un número posterior, otros referentes confesamente contrarios a la apuesta marxista, y muy lejos de cualquier institucionalidad en Cuba, como el propio Rafael Rojas (2008), asumirían sin mayor objeción que, efectivamente, entre otros pensadores, Guadarrama forma parte de aquella "reacción intelectual contra el marxismo-leninismo soviético" (p. 27). Con tal afirmación, y más allá de cierto reacio liberalismo a ultranza, Rojas reconoce la apuesta de Guadarrama contraria a la mencionada usanza dogmática.

$\overline{\text { 6. Cuestiones que, }}$ sin mayores concesiones ni distinciones, relegan bajo el rótulo de "escolástica marxista" a la mayor parte de todo lo que bajo ese sello se haya escrito o construido o intentado construir en la práctica.

7. El mencionado autor llega al extremo de considerar que "el marxismo como filosofía es una farsa" y resulta significativo, además, que la referencia a Guadarrama la haga desde las páginas de la mismísima revista Encuentro de la Cultura Cubana, editada en Madrid, contraria por demás a cualquier proyección marxista y lejos, muy lejos, de cualquier implicación favorable a la apuesta de Cuba durante el último medio siglo, de la que Guadarrama es abiertamente partidario. 
Resulta además significativo que desde el ámbito anglosajón dominante en los planos de la crítica filosófica, obras de Guadarrama como América Latina: Marxismo y Postmodernidad (1994), entre otras, hayan sido referenciadas en Routledge Encyclopedia of Philosophy (edición general de Edward Craig en 1998), como un relato o perspectiva de tipo "ortodoxa" sobre la crisis del marxismo en los noventa ${ }^{8}$. Y resulta significativo toda vez que, aún cuando no especifica para tal caso particular con cual noción de ortodoxia está operando Routledge, paradójicamente sí que sitúa y reconoce de modo referencial la obra de Guadarrama como una apuesta por entender la referida crisis operada en el marxismo en la década de los noventa del siglo XX, una apuesta crítica difícilmente posible de hacer sin desmarcarse del dogmatismo al que precisamente enjuicia la edición de Craig.

Lo textos de Guadarrama integran, in extenso, los fondos de las más importantes y prestigiosas bibliotecas y universidades de todo el mundo y también los fondos de austeros y pequeños espacios donde su obra resulta todavía más valiosa. Durante más de tres décadas las referencias a la obra de Guadarrama han ganado espacio en el estudio de la historia de las ideas en América Latina, y su extensa producción resulta de consulta obligada para el estudio de la historia del pensamiento latinoamericano desde sus inicios hasta las fechas más recientes, haciéndose presente tanto en múltiples referencias a textos de su autoría como a la reseña directa de su trabajo o de su trayectoria en ediciones diversas sobre el legado filosófico latinoamericano.

Si bien es cierto que la trayectoria de Guadarrama lega de un modo significativo a los estudios de pensamiento filosófico latinoamericano en términos de rescate del pensamiento de autores y en términos de su aporte teórico mismo, también habría que destacar que, sin distanciarse de ello, y en el marco de lo anterior, su trabajo, además, ha incluido el tratamiento de problemáticas de gran relevancia sociopolítica en la actualidad de su momento histórico. Temáticas que, por su planteamiento mismo y por la fecha de su publicación, ya confirman su rápida respuesta a las contingencias y necesidades de tu tiempo. No es un filósofo dedicado a lo meramente abstracto.

Dentro de la larga lista de trabajos que en este último sentido ha aportado, y por el cual también es referenciado, pudieran destacarse, entre otros muchos, libros, artículos, capítulos de libro y/o

8. Literalmente referenciado como "An orthodox Cuban Marxist's account of the 1990s crisis of Marxism". 
ponencias como: Antimonias en la crisis del socialismo (1992); "El fin de la historia: un mito que se esfuma" (1994); “¿Derrumbe del socialismo o del marxismo? Después de la polvareda, desde la atalaya latinoamericana" (1994); "Fuentes y perspectivas del neoliberalismo. Pensamiento alternativo vs. pensamiento único" (2001); "El Marxismo y las posibilidades del socialismo en Cuba" (2002); "Desafíos educativos y culturales de la globalización para América Latina" (2002); "El Pensamiento de la integración latinoamericana ante la globalización" (2004); "Critica del paradigma posmodernista en su impacto educativo e informático-comunicativo" (2005); Cultura y educación en tiempos de globalización posmoderna (2006); "Fidel Castro, ¿líder insustituible?” (2006) (referido a una problemática de especial y trascendente relevancia para Cuba); "Crítica a los reduccionismos epistemológicos en las ciencias sociales" (2007); "Comunicación y socialismo del siglo XXI" (2007); "El conflicto entre las bases filosóficas del derecho moderno y posmoderno" (2008); "Las nuevas izquierdas latinoamericanas y la cuestión del poder" (2008); "La calidad educativa y la perspectiva ideológica ante la racionalidad instrumental globalizada" (2008); "Los derechos humanos ante el conflicto modernidad y posmodernidad" (2008); "Democracia y derechos humanos: ¿conquistas exclusivas de la cultura occidental?" (2009); "Cultura, mentalidad, cultura y ciudad" (2010); -Estado, democracia, poder y administración pública- (2011); "El socialismo del siglo XXI: perspectiva de los marxistas latinoamericanos" (2012); "Algunos debates sobre derechos humanos y sistemas jurídicos" (2012); "El socialismo latinoamericano" (2013); "La praxis investigativa y pedagógico-educativa latinoamericana ante las ideologías, los obstáculos epistemológicos y el pragmatismo" (2013); "La educación superior en la superación de los obstáculos para la integración latinoamericana" (2014), etc.

Dicho todo lo anterior, bien valdría considerar algunas claves fundamentales de la obra de Guadarrama que le hacen ser precisamente un referente tanto de los estudios de pensamiento filosófico latinoamericano como del marxismo humanista y que ha desarrollado con sello propio a lo largo de toda su vida.

\section{De las claves del marxismo humanista de Guadarrama}

En su voluminosa Historia del Pensamiento filosófico latinoamericano. Una búsqueda incesante de la identidad, en el apartado destinado 
a la filosofía marxista, Carlos Beorlegui (2004) hace especial mención al trabajo de Guadarrama:

En su obra se diferencian claramente dos periodos: uno vinculado a la filosofía marxista ortodoxa, ligada a la metodología marxista-leninista, y otro, más crítico respecto a la etapa anterior, en el que sin abandonar la orientación marxista se vincula a esta filosofía de modo más flexible y distante. (p. 809)

No obstante, aún cuando se asumiese tal intento de periodización de la obra de Guadarrama, habría que acotar que, tanto en un momento como en el otro, la dimensión crítica desde el valor de lo propio no estuvo nunca ausente, sino que más allá de algunas correcciones entendibles en el marco de su contexto, la apuesta por la crítica y por el rescate de lo propio, en términos de historia de las ideas, ha sido siempre una constante en todo su trabajo:

Sin hubiéramos de sintetizar en un componente la línea central de la filosofía de Guadarrama, tendríamos que hacer referencia a su preocupación por lo humano, por la dimensión humanista del filosofar, cualidad y preocupación que él ve como uno de los rasgos específicos del filosofar latinoamericano. (p. 810)

Y es que, unido a lo anterior, habría una serie de particularidades de la apuesta de Guadarrama que merecen ser consideradas en un texto como el que aquí se presenta. Para esta ocasión valgan a tales efectos destacar el lugar de la crítica, su necesidad y su asunción como herramienta irrenunciable, el lugar de lo propio como valor emancipatorio en su obra, y en función de esto último la consideración de conceptos claves en el desarrollo del pensamiento latinoamericano como los de autenticidad, originalidad, lo específico y lo universal. Todo ello conjugado en una apuesta emancipatoria por el humanismo como contraposición a la enajenación, tanto en el orden del pensamiento, como en su manifestación en la praxis.

Para dar tratamiento a tales cuestiones, corresponde, además, precisar antes el marco epistémico desde el que Guadarrama concibe las funciones de la filosofía, y en particular su rol frente al desarrollo del pensamiento latinoamericano. En tal sentido habría que destacar dos trabajos de suma relevancia: "¿Qué historia de la filosofía se necesita en América Latina?” y “¿Para qué filosofar? (Funciones de la filosofía)”, publicados en 1997 y 1998, respectivamente. 
En la conjunción de ambos trabajos, el autor villaclareño puntualiza cuestiones epistémicas claves que regirán toda su obra. En el primero de ellos apuntala cuestiones determinantes de su apuesta humanista en clave latinoamericanista a la que haremos referencia en detalle en los apartados siguientes. Y en el segundo queda claro que la filosofía implica, desde la perspectiva que Guadarrama (1998) asume, una serie de funciones consustanciales, definidas en diez puntos: 1 . cosmovisiva, dada en saber, comprender, pronosticar; 2. lógico-metodológica, dada en examinar y analizar; 3. axiológica, dada en valorar, enjuiciar y apreciar; 4. Hegemónica, dada en dominar y controlar; 5. práctico-educativa, dada en transformar, cultivar, superar; 6. emancipatoria, dada en liberar y desalienar; 7. ética, dada en comportar y conducir; 8. ideológica, dada en orientar y disponer; 9. estética, dada en disfrutar y gustar; y 10. humanista, dada en perfeccionar, progresar y humanizar (pp. 109-139).

Ahora bien, en tal mosaico advierte la existencia de una jerarquía de funciones. Y así, consideraría que las funciones axiológica, hegemónica, práctico-educativa, emancipatoria, ética y estética quedan subsumidas en la función axiológica propiamente dicha y articuladas a la función ideológica. Entendiendo además lo ideológico no como falsa conciencia o simple imagen pretensiosa de la realidad social, sino como conjunto de ideas que conforman la concepción de una clase o grupo social, dirigidas al sostenimiento o realización de su poder respecto a toda la sociedad, o al menos a nombre de ellas.

Y obviamente, a juzgar por la definición y tratamiento que Guadarrama da a las otras dos funciones, lógico-metodológica y cosmovisiva, también estas quedan contenidas a lo largo de la historia en función de determinada concepción de clase y su correspondiente manifestación específica en un contexto u otro. De la función cosmovisiva destacaría, además, que habría sido una de las que más distinguió a la filosofía desde sus primeras manifestaciones hasta nuestros días, y siendo su particularidad la de saber, comprender y pronosticar, estarían también condicionados por el desarrollo de lo lógico-metodológico, y tanto unas como otras se circunscribirían precisamente al principio de historicidad a lo largo de todo el desarrollo humano. $\mathrm{Y}$ en específico con relación a la función lógico-metodológica de la filosofía, apuntaría que esta se articularía mucho más a la hegemónica, pues precisamente proporciona al hombre las armas conceptuales que le permitirían ejercer su dominio, no solo sobre la naturaleza, sino sobre la sociedad y su control sobre sí mismo. Y destaca además que, desde que la filosofía se constituye en actividad intelectual específica, 
la función humanista ha estado presente como elemento consustancial a toda reflexión cosmovisiva?.

En ambos trabajos mencionados de 1997 y 1998, queda claro que Guadarrama apuesta por una reconfiguración del valor de lo filosófico y de la filosofía, no como mera descripción de los fenómenos, sino desde una toma de consciencia que gana especial relevancia emancipatoria afincada desde lo latinoamericano. Con toda seguridad, tal reconfiguración está en sintonía con la conocida tesis once de Marx sobre Feuerbach, en la que el Prometeo de Tréveris sentenciaba que "los filósofos no han hecho más que interpretar de diversos modos el mundo, pero de lo que se trata es de transformarlo".

La labor del investigador de la historia de la filosofía no es, entonces, meramente descriptiva y explicativa del pasado, sino que para Guadarrama ha de ser también pronosticadora de las posibles tendencias o rumbos por los que puede discurrir la evolución futura del pensamiento filosófico. Y en ese algo más, ese ir más allá del frecuente vedetismo intelectual en publicaciones y congresos de filosofía, Guadarrama (1997) invoca como objetivo de primer orden para los estudios filosóficos el llamado a la toma de conciencia. Para el pensador villaclareño es más necesaria una historia de la filosofía que revele en qué medida las ideas de un pensador han sido más provechosas a la comunidad humana, más allá de cualquier frontera, aunque haya que comenzarla a medir, en primer lugar, por el efecto en su entorno.

No sería entendible además la obra de Guadarrama si ella misma, y el propio Guadarrama, no es contextualizado. Tal y como ya ha sido referido, Guadarrama encausa su producción académica proviniendo de un contexto de formación que tuvo sus pilares en Cuba y en Alemania en tiempos del campo socialista (RDA), en la cual las fuentes de la tradición filosófica occidental, desde una proyección dialéctico-materialista inscrita en la lógica del marxismo-leninismo, se conjugaron con el propio pensamiento cubano y latinoamericano. Su trayectoria, además, no pudiera ser entendida sin considerar su inscripción directa en el marco de la Revolución Cubana y todo lo que un proceso de tales dimensiones representó tanto para Cuba como para Latinoamérica, así como para pensadores que, como Guadarrama, han hecho patente desde un primer momento su compromiso intelectual y político.

En este último sentido, ante la circunstancia histórica a la que se vieron abocados buena parte de los pensadores marxistas a finales

9. A efectos de tal argumentación in extenso, remítase a la referencia anterior. 
de la década de los ochenta y durante buena parte de la década del noventa del siglo XX, Guadarrama respondió a la disyuntiva en un momento raigal en 1989. Y así, en su trabajo "Hay crisis entre los marxistas latinoamericanos" $(1989)^{10}$ pone sobre la mesa, de modo claro y sin rodeos, las claves del por qué apostar por la reivindicación del método hallado en Marx y en Engels en un momento de desazón reinante, un momento tan álgido como los albores del que sería denominado, poco después, como "el fin de la historia".

Aquel fue un artículo significativo, en el que quedaría reflejada de modo preciso la postura de Guadarrama en cuanto a una problemática de envergadura mayor en el desarrollo del pensamiento revolucionario latinoamericano. En él da respuesta a autores como Agustín Cueva (1974), quien ya no solo negaría el valor filosófico de Marx mismo sino que habría invertido los términos y, en lugar de hallar en El Capital una apuesta por la crítica al modo de producción capitalista y a la enajenación en sus diferentes formas derivada de ello, así como la consecuente crítica al régimen de explotación que somete al obrero, asumiría por el contrario que El capital no sería más que el largo y aburrido análisis de la forma prosaica que asume para los obreros el noble concepto de alienación (p. 124). Sin duda alguna, una aberración teórica en toda regla. Pero en un sentido similar, autores como Víctor Moncayo (1983) aspirarían a "poner fin a las orientaciones que quieren hallar en Marx un método, una nueva epistemología" y, lejos de reconocer cualquier valor científico social o emancipatorio en Marx, directamente le juzgarían como "un artífice de la ciencia de la subversión, de la necesidad de desencadenar, a partir del antagonismo, la destrucción de la relación que sustenta y lo reproduce; no un científico social, como muchos quieren denominarlo para tener un par de alta alcurnia, sino un científico antisocial...” (p. 25).

En aquel contexto marcado por tal tono visceral, un tono por demás premiado en las academias dueñas de la hegemonía en términos filosóficos y políticos, Guadarrama apostaría por reivindicar precisamente el carácter filosófico, científico y emancipatorio de la obra de Marx, Engels, Lenin y de la tradición marxista. Y lo hizo desde la crítica y no desde el dogma. Así como también reivindicó el marxismo que, en clave propia, intentó desde América Latina dar respuestas a los problemas propios. Lo haría, además, desde la proximidad y no

10. También incluido en el libro Marxismo y antimarxismo en América Latina, editado por la Universidad INCCA de Colombia, Bogotá, 1990. 
desde el absoluto distante marcado por la manualística a la que autores como Moncayo o Cuevas se estarían refiriendo, sesgadamente, en nombre de toda la obra de Marx en sí misma ${ }^{11}$. Asumir entonces una reivindicación del materialismo dialéctico podía ser solo desde la crítica. Y en ella y desde ella se conjugaría desde un inicio su apuesta por lo propio.

\section{La crítica como herramienta irrenunciable}

Ante circunstancias como las anteriormente referidas, ha sido la crítica consecuente y su matriz metódica de fondo la que ha guiado la producción de Guadarrama, unida ésta a un sentido del compromiso intelectual y político con la historia y con la realidad de los pueblos. La apuesta por la crítica ha sido siempre uno de los intereses manifiestos que ha conducido la labor investigativa y docente de Guadarrama. De modo que aquel precepto esbozado por Marx en cuanto a la "crítica crítica" se ha metabolizado y hecho letra impresa en los muchos textos por él escritos o coordinados. Tal intención de someter a consideración crítica ha sido una constante en las obras que Guadarrama nos ha legado a lo largo de su vida. Así, desde sus primeras obras significativas, el propio hecho de desafiar la estereotipia de la filosofía como predio del occidente europeo y dedicarse al rescate de la obra filosófica de autores cubanos y latinoamericanos esbozó tempranamente, y con contundencia, el sendero que encausaría a lo largo de toda su vida. Tal perfil quedó ya esbozado desde sus Valoraciones sobre el pensamiento cubano y latinoamericano, en 1985.

Tales Valoraciones condensarían los resultados de años de investigación desde que, en 1973, Guadarrama trabajara la temática del positivismo de Enrique José Varona, y en cuya figura se centraría en los años subsiguientes en función de sus ideas éticas y sociopolíticas, el ateísmo y el anticlericalismo, así como la sociología en el pensamiento del eminente camagüeyano. Esto se extendió a autores como Manuel Sanguilly (1978), Enrique Piñeyro (1979) y su papel en la introducción del positivismo en Cuba, la influencia del positivismo en Emilio Bobadilla (1980), el positivismo en la obra de Fernando Ortíz (1981), así como el positivismo comtiano de Andrés Poey (1982), y en este propio año las particularidades del positivismo en

11. Sin lugar a duda, tales posturas no encarnaron otra cosa que uno de los tantos quid pro quo que ha caracterizado la historia de la crítica a Marx, como también a la visceral denigración del marxismo. 
Cuba. También centraron su atención en aquellos años iniciales el pensamiento filosófico de José Agustín Caballero, Félix Varela y José de la Luz y Caballero (1983) y el análisis de las principales corrientes y sus representantes del pensamiento filosófico cubano de la primera mitad del siglo XX (1983), así como la imagen de Marx en la filosofía latinoamericana contemporánea (1984). Todo lo cual sería apenas el inicio de una extensa producción reivindicativa de lo propio en términos de pensamiento filosófico.

No sería posible asumir el reto del rescate del pensamiento de tales autores, y todos los que en lo sucesivo Guadarrama trataría, si no se asumiese una perspectiva propiamente crítica en cuanto a lo que tradicionalmente había sido considerado como filosofía desde una perspectiva excluyente y etnocéntrica. Desde entonces, a la fecha, el trabajo de Guadarrama ha incluido el rescate y el tratamiento de un amplio espectro de autores que han tributado al desarrollo del pensamiento latinoamericano. Y sobre la base de tales análisis ha insertado su propio aporte teórico.

Precisamente, en la presentación de la primera edición que se hiciese en Colombia de Lo universal y lo específico en la cultura (Guadarrama y Pereliguin, 1988), Jaime Quijano-Caballero, rector de la Universidad INCCA, apuntaría que tal obra tributaría al llamado "movimiento crítico" (pp. IX-XV) que se había impulsado desde la facultad de filosofía de la referida universidad desde inicios de los años ochenta. La mencionada obra de Guadarrama daba respuesta al llamado que, como parte de tal movimiento, se había hecho a una reflexión global, a un criticismo dinámico y complejo, sobre la esencia de las fuerzas motrices que impulsan los cambios sociales revolucionarios en "nuestros pueblos" (pp. IX-XV). Y dentro de tales cuestiones tendrían especial relevancia, precisamente, los cuestionamientos sobre el papel de la filosofía y la cultura en los pueblos latinoamericanos. De modo que la reflexión filosófica contenida en aquella obra, se presentaba expresamente desde su trasfondo propiamente crítico y en perspectiva latinoamericanista. Desde el llamado a la crítica se hacía, y a la crítica tributaba.

Así también, a propósito de Marxismo y antimarxismo en América Latina (1990), en el “¿Porqué y para qué de este libro?”, el propio Guadarrama advertiría sobre el lugar de la crítica en la configuración de aquel proyecto editorial llamado a repensar de modo crítico los análisis que desde el referente marxista se operaban en aquel momento álgido tanto para la praxis como para la sostenibilidad del discurso marxista en América Latina: 
Queríamos verificar si resultaban válidas algunas críticas al marxismo, por ejemplo, el tacharlo de europeísmo, exotismo, dogmatismo, etcétera. O si, por el contrario, nuestros marxistas en lugar de plantearse la elaboración de sistemas teóricos apriorísticos y especulativos, como es común en el pensamiento burgués, se habían dado a la tarea de estudiar sus respectivas realidades concretas y a la vez nutrirse de las formulaciones teóricas emanadas de la doctrina marxista en tanto que la enriquecían y enjuiciaban. (p. XXXV)

Desde esta tesitura reconocería además la motivación de la crítica para la articulación de un discurso desde lo propio, en el cual se conjugase de modo abierto tanto la recepción de la crítica desde marcos epistemológicos desmarcados del marxismo, como, sobre todo, la propia crítica a la perspectiva propia. Definitivamente, una apuesta dialéctica coherente con los fundamentos críticos del método dialéctico-materialista, alejada, muy alejada de cualquier dogmatismo argumental:

También nos motivaba la idea de que el marxismo, por su esencia genuina, no reserva el arma de la crítica solamente para sus adversarios, sino que la utiliza como constante fermento catalizador de perfeccionamiento de sus propias elaboraciones teóricas, acorde con las nuevas circunstancias que emanan de las nuevas contradicciones engendradas por la práctica social, sin renunciar a las tesis fundamentales de la concepción dialécticomaterialista, y por tanto histórica, del mundo. (pp. XXXV-XXXVI)

A lo largo de toda su obra, las referencias al lugar de la crítica, más que una recurrencia, se trata de un fundamento constitutivo de todo su trabajo. Un trabajo cuyo resultado se ha encaminado siempre a hallar y brindar instrumentos para la reflexión efectivamente crítica. Tal y como apuntase en la presentación a la segunda edición de Lo universal y lo específico en la cultura, pretendía ser, precisamente, "un instrumento de reflexión desde la perspectiva latinoamericana de estos tiempos" sobre un tema tan colosal como el que desde el mismo título se anunciaba, y que ha movido y seguirá moviendo, según el mismo Guadarrama, el intelecto de filósofos, sociólogos, críticos de arte, antropólogos, etc.

La crítica más allá de sus consecuencias, la crítica como necesidad determinante para el pensar consecuente con la realidad operante en los pueblos y no agotada en lo meramente discursivo o teórico. Una dimensión por el filtro de la cual habría de pasar también el legado 
de la propia tradición en la cual su pensamiento se inscribe. Así, en Despojados de todo fetiche (1999), el objetivo habría sido "someter a consideración crítica algunas de las ideas principales del marxismo, especialmente en su dimensión filosófica, ideas que han motivado el interés de la intelectualidad latinoamericana (p. VIII). Un título el de aquella obra colectiva que tendría como referente el criterio del controvertido marxista mexicano José Revueltas, en cuanto a que "No debemos esperar de nadie, sino de nosotros mismos: pensar, escribir, luchar, con audacia, despojados de todo fetiche, de todo dogmatismo, no importa al punto en que lleguemos" (p. 421) ${ }^{12}$.

Tal ejercicio crítico del pensar, Guadarrama lo ha hecho praxis también en su magisterio, en el cual, tanto como en la investigación, "la duda metódica" encuentra también un lugar determinante para la construcción del conocimiento. "La duda es madre de la investigación”, dijo Galileo Galilei, y este ha sido precisamente uno de los preceptos que ha subyacido en la obra del pensador villaclareño. Incluso en el orden de su magisterio, quienes hemos escuchado a Guadarrama sabemos que siempre en su praxis como maestro deja abierta y hace expresa la invitación a la duda como herramienta para la construcción del conocimiento. Su análisis lo presenta como el propio, eso sí, pero abierto siempre a la consecución más estricta de la crítica, en la cual su propio argumento defendido queda dispuesto y expuesto también al filtro de la duda y a su coherente crítica. No presenta la docta tabula rasa del sapiens dogma, sino que su pedagogía asume el precepto aristotélico de que la duda es el principio de la sabiduría, y desde esa perspectiva invita al estudiante y al colega a dialogar sobre sus argumentos, escenificando la idea baconiana y cartesiana de llegar a las certezas precisamente a través del dudar, a través de la utilidad de la duda metódica para la construcción del saber crítico. Y es, ahora sí, sin duda alguna, Marx (con toda la herencia en él implícita) quien suministra su contundente perspectiva crítica en conjunción con la tradición latinoamericana, especialmente desde la ética martiana, desde la que el maestro santaclareño construye su análisis y su praxis.

El método crítico desde el que opera Guadarrama (2001) se sustenta sobre la base del principio de historicidad en la investigación histórico-filosófica, el cual, a su propio decir, presupone tomar en consideración la época histórica en que aparecen determinadas ideas como reflejo de esas condiciones, pero no como simple imagen pasiva de estas (p. 89). Ahora bien, en cuanto a América Latina se refiere,

12. Expresión esta, "despojados de todo fetiche", que el propio Guadarrama subrayaría. 
Guadarrama apuntaría que, teniendo en cuenta la relativa independencia de las formas ideológicas respecto a las condiciones materiales de existencia, puede entenderse por qué, a pesar del marcado retraso socioeconómico respecto a Europa y Norteamérica, pudieron aparecer pensadores y corrientes de ideas que expresaban de modo sui generis el nivel del pensamiento filosófico universal de su época en sus respectivos países (p. 89).

La crítica en Guadarrama, entonces, está articulada sobre la base del método dialéctico-materialista, a partir del cual despliega la metodología propia de la historia de las ideas, y la aplica desde el reconocimiento de lo propio como valor:

La investigación histórico-filosófica que pretenda apoyarse en una concepción dialéctico-materialista del mundo tiene el deber de asumir con todo el rigor científico necesario la delimitación de los aportes de cada pueblo al tesoro del pensamiento filosófico y la cultura universal. Esto implica hurgar en el pasado y descubrir, a veces en el olvido, a pensadores que a pesar de no haber dejado voluminosas obras filosóficas han formulado ideas, incluso en ocasiones en forma aforística, o en el contexto de una obra literaria, pero que por el valor y significado trascienden su época y pueden ser esgrimidas por las nuevas generaciones, aunque aquellas hayan sido planteadas en un contexto histórico diferente. (p. 94)

\section{Autenticidad, originalidad, especificidad y universalidad en Guadarrama}

Como parte de este hurgar en el pasado, y en sintonía con su contextualización presente, merece además que sean considerados otros elementos fundamentales en la valoración de lo propio en la obra de Pablo Guadarrama. Pudiera asumirse lo propio como aquello que es relativo, correspondiente o perteneciente al uno mismo, sea este individual o colectivo. Tal uno mismo remite necesariamente al sentido de lo particular y de lo específico del sujeto histórico que se es en un contexto concreto. En el caso del pensamiento latinoamericano, lo propio del ser latinoamericano es complejo y no idéntico (si se entendiese aquí lo idéntico como una cosa que es lo mismo que otra). En la historia de tal pensamiento lo propio del ser latinoamericano encuentra un referente conceptual determinante en la perspectiva que manejase José Martí en el ensayo Nuestra América y que ha tenido continuidad hasta hoy en múltiples autores que coinciden en referirse a lo propio 
en mayor o menor medida en términos de identidad, pero conjugando en el análisis entre otros preceptos lo auténtico, lo original, lo especifico y lo universal.

El sentido de lo propio ciertamente ha estado contenido en múltiples esquemas y/o sistemas filosóficos a lo largo de toda la historia, pero más allá de secuenciaciones o definiciones exactas en sentido abstracto a lo largo de los siglos, de lo que se trataría en este caso es de considerar el lugar que tal invocación tiene como contenido emancipatorio en la complejidad argumental con la que opera el autor villaclareño. Y he aquí entonces la vuelta a la pregunta por lo auténtico, por lo original, por lo específico y por lo universal en la cultura, en función de lo concreto y no desde la mera abstracción del concepto. Nociones tras cuyo tratamiento son identificables las herencias recientes, entre otras muchas, de Leopoldo Zea, Augusto Salazar Bondy o Francisco Miró Quesada.

Nadie se cuestiona, diría Guadarrama, que han sido auténticas las filosofías producidas en otras partes del mundo, especialmente en Europa y Estados Unidos de Norteamérica; no obstante, no sucedería lo mismo para con las filosofías producidas en América Latina, toda vez que estas se inscriben en un marco de relaciones determinadas por lo hegemónico en términos culturales y filosóficos. El problema del derecho a ser de la filosofía latinoamericana, considerarían Guadarrama y Pereliguin (1998), no constituye una simple cuestión de disquisiciones intelectuales, sino que tiene profundas raíces ideológicas y está aparejado al reconocimiento de todo el valor de la cultura latinoamericana (p. 118) ${ }^{13}$. Y asumiendo que la identidad y autenticidad latinoamericanas son históricas y concretas, y que no han sido dadas de una vez y por todas, defiende, no solamente que existen, sino que hay que cultivarlas, definirlas y proclamarlas a todas voces para su necesaria concientización (Guadarrama, 2001, p. 97). Y en función de ello ha encaminado precisamente su prolífero trabajo.

Las mencionadas formas sui generis en el pensamiento latinoamericano han tenido continuidad tanto en la praxis investigativa como pedagógica del maestro villaclareño. Tal y como él mismo afirma, la conocida expresión de que toda idea es crítica presenta plena validez en el análisis del proceso de formación de la autoconciencia del latinoamericano, y en función de ello tributa toda su obra: 
El conocimiento de "sí mismo" (del latinoamericano) se plasma ante todo en el estudio crítico de su historia. Para la concientización de su autenticidad era imprescindible emanciparse de los modelos tradicionales de la historia, que amoldan la de los pueblos dominados a la de los dominadores. (p. 95)

Guadarrama siempre ha tenido claro que la discriminación que ha sufrido el pensamiento latinoamericano desde los referentes hegemónicos en los ámbitos de la filosofía se ha debido no precisamente a cuestiones de índole meramente cognoscitivos, académicos o de argumentación propiamente dicho, sino que a ello subyace una matriz más compleja, en la que la intervienen factores históricos en los órdenes de lo político, lo económico y lo cultural. Así, y como es de entender desde una aproximación marxista al tratamiento de la historia de las ideas en América Latina, en Guadarrama está muy presente la dimensión concreta de la realidad latinoamericana y los condicionantes materiales, económicos y de clase que han determinado y determinan la evolución del pensamiento filosófico en esta región del planeta. Y develando consecuentemente el rechazo, tolerancia y/o aceptación de este desde los ámbitos que hegemónicamente rigen el mundo en términos, ya no solo filosóficos, sino también culturales.

En cuanto a ello, Guadarrama y Pereliguin (1988) asumen que el problema de la autenticidad de las culturas y su participación en la universalidad no es un tema reciente, de modo que en cuanto a la pregunta por la autenticidad de la cultura latinoamericana realiza un recorrido histórico del desarrollo de tal formulación, asumiendo que las reflexiones sobre el lugar, los valores y los problemas de la cultura latinoamericana son de vieja data (p. 53). Y precisa que la lucha contra el colonialismo en los diversos pueblos del mundo ha estado acompañada por un proceso de identidad cultural, originalidad, etc. (p. 65), en cuyo transcurso han destacado autores a los que pormenorizadamente se refiere, algunos de los cuales serían intelectuales preocupados por la autenticidad y la universalidad de la cultura latinoamericana como Alejo Carpentier, Jorge Luis Borges, Augusto Salazar Bondy, Leopoldo Zea o Enrique Dussel, entre otros.

Así como Leopoldo Zea entiende la originalidad como "la capacidad para hacer de lo propio algo universal, válido para otros hombres en situación semejante a la propia", el problema, a decir de Guadarrama y Pereliguin, no consiste en descubrir primero qué es lo que debe ser considerado auténtico, para después ir verificando empíricamente si cada manifestación de la cultura de esta región puede ser validada con tal requerimiento (pp. 141-142). "La cultura 
auténtica - continuarían afirmando en línea con Zea- es siempre específica y por tanto histórica y debe ser medida con las escalas que emergen de todos los demás contextos culturales, pero en primer lugar de las surgidas del mundo propio (p. 142).

Considerando entonces la idea de F. Miró Quesada y de Leopoldo Zea en cuanto a la definición de qué sería hacer filosofía auténtica, es decir, en palabras de Zea, "una filosofía que no fuera una copia mal repetida de filosofías importadas”, Guadarrama (2001) distinguiría que:

En la historia universal una filosofía ha sido original y auténtica no cuando ha planteado simplemente ideas nuevas, sino cuando estas se han correspondido con las exigencias históricas de su momento en los diferentes planos, esto es, en el orden sociopolítico, económico, ideológico y científico. (p. 91)

De modo que, en él, el sentido de la autenticidad va más allá de lo meramente original en términos de lo nuevo y está dado en términos de contextualización a unas condiciones y necesidades específicas:

Auténtico debe ser considerado todo aquel producto cultural, material o espiritual que se corresponda con las principales exigencias del hombre para mejorar su dominio sobre sus condiciones de existencia, en cualquier época histórica y en cualquier parte, aun cuando ello presuponga la imitación de lo creado por otros hombres. De todas formas, la naturaleza misma de la realidad y el curso multifacético e irreversible de la historia le impone su sello definitivo. (p. 96)

$\mathrm{Y}$ es desde esta perspectiva, entonces, que Guadarrama entiende y asume su apuesta por lo latinoamericano en términos filosóficos y reconfigura la noción de lo universal y lo específico en el rol de la filosofía en América Latina ajustada a unas necesidades históricas concretas:

La filosofía en América Latina no solo ha desempeñado el papel de comprensión teórica de su respectiva época, sino de instrumento de toma de conciencia para la actuación práctica. Solo de esa forma es posible entender por qué la mayoría de los pensadores latinoamericanos más prestigiosos en lugar de construir especulativos sistemas filosóficos, han puesto su pluma al servicio de las necesidades sociopolíticas de sus respectivos momentos históricos, y en tal sentido han adoptado una postura más auténtica. (p. 90) 
Ahora bien, para Guadarrama el reconocimiento de la identidad no puede ser un logro en sí mismo, sino un paso necesario hacia la exigida autenticidad cultural. Y en tal sentido reconoce que los pueblos latinoamericanos han dado pasos decisivos desde el siglo pasado para redimirse y hacer auténtica su cultura, de manera que aboga por "hacer todo lo posible para revelarla permanentemente en cada lugar en que el hombre latinoamericano requiera ser dignificado para sentirse auténtico más que idéntico" (p. 97).

En ese hacer todo lo posible por develarla, la reivindicación de lo propio tiene en Guadarrama un fuerte valor emancipatorio, y es por ello por lo que, en su Epílogo a Positivismo y Antipositivismo (2004), dedicase una reflexión de cierre a "pensar con cabeza propia":

Pensar con cabeza propia no significa asumir posturas de chauvinismo epistémico y cerrarse a los aportes del pensamiento provenientes de cualquier parte del mundo. Tampoco presupone desconocer el valor intelectual o de otro carácter de pensadores con los cuales se puede, incluso, coincidir parcial o totalmente. Por el contrario, significa asumirlos, pero no indiferenciadamente, sino en correspondencia con las exigencias cognoscitivas, axiológicas e ideológicas que cada momento reclama. Se ha de medir con mayor rigor los grados de autenticidad de dicho pensamiento que los de originalidad, si por tal solamente se entiende su carácter novedoso. (pp. 383-384)

Pensar con cabeza propia, para Guadarrama, implica, además, reivindicar justamente la condición humana. Y puede en función de ello entenderse entonces su apuesta emancipatoria por el humanismo. Un tema que, tal y como reconocería en su nota introductoria a José Martí y el humanismo en América Latina (2003), le habría motivado desde sus primeros estudios sobre la trayectoria del pensamiento latinoamericano (p. 9).

\section{La apuesta emancipatoria por el humanismo versus enajena- ción}

Como se ha dicho, la apuesta emancipatoria por el humanismo tiene un determinante contenido crítico y reivindicativo de lo propio. De manera que, en tal sentido, otros de los componentes centrales de la obra de Guadarrama son el lugar que en ella ocupa el humanismo como contenido de investigación y el carácter humanista que su 
obra misma encarna. En cuanto a lo primera valga señalar el extensa trabajo de rescate del pensamiento humanista latinoamericano, entre muchos de los cuales, y por solo citar algunos, tienen especial espacio el humanismo práctico de José Martí asumido como humanismo revolucionario y liberador, el humanismo de Enrique José Varona ante la condición humana, el humanismo vital de José Enrique Rodó, el humanismo americanista de Pedro Henríquez Ureña o la dimensión concreta de lo humano desde la perspectiva de José Carlos Mariátegui.

En cuanto a su apuesta emancipatoria, valga señalar, además, que Guadarrama asume el humanismo como contraposición directa a la enajenación, y en tal sentido encamina su reflexión como herramienta desalienadora. En cuanto a la enajenación, especificaría que estaría siempre condicionada por el insuficiente conocimiento que el ser humano posee sobre aquellas fuerzas que le parecen muchas veces hostiles hasta el momento en que se le revelan en todas sus dimensiones y se percata de su carácter endeble (p. 123).

Si bien es cierto que la filosofía, a decir de Guadarrama (1985), "le concede al hombre lo que la religión le niega: la comprensión de sus capacidades, tratando de arrancarle la falsa imagen que él tiene de sí mismo" (p. 121), el propio autor pone en duda, además, que la filosofía en sí misma implique la efectiva liberación o superación de la alienación, de modo que, aún cuando la filosofía en toda época y lugar haya tenido pretensiones liberadoras y desalienantes, no significa que siempre lo haya logrado, o que deban ser consideradas todas las filosofías precedentes como antecedentes imprescindibles ${ }^{14}$ de una apuesta liberadora en el pensar (Guadarrama, 1993, p. 173).

Cualquier forma de enajenación debilita en definitiva el poderío humano frente a aquellos objetos de su creación que deberían estar siempre destinados a enriquecer la plenitud humana, pero resulta todo lo contrario, y Guadarrama (2001) advierte que tales creaciones humanas, en lugar de contribuir al perfeccionamiento de lo humano y elevar a planos superiores la actividad del hombre, llegan, por cuenta de la enajenación, a obstaculizarla (p. 100). Así, concordando con el criterio manejado por István Mészáros en cuanto a la consecuente exclusión derivada de la enajenación, Guadarrama asumiría que si bien es cierto que "el concepto de enajenación y enajenabilidad implica exclusión, el concepto de humanismo por el contrario, presupone siempre asunción, incorporación, ensanchamiento de la capacidad

14. Tal apunte Guadarrama lo refiere en cuanto a la Filosofía de la Liberación en concreto, pero es extensible su semántica también a otras filosofías con pretensiones liberadoras. 
humana en beneficio de la condición humana" (pp. 100-101). Y por medio de su apuesta humanista, Guadarrama (1998) encauza su ideal emancipatorio, el cual, entre otras cosas, apuesta porque la filosofía cumpla mejor su función emancipatoria:

La lucha entre el pensamiento humanista y las distintas formas de enajenación ha existido desde los primeros momentos en que el hombre tomó conciencia de especial situación en el mundo respecto a la naturaleza y la sociedad. Esta ha sido una constante y parece que siempre ocurrirá así. (Guadarrama, 2008, p. 111)

Y así, el humanismo que Pablo Guadarrama postula se presenta en contraposición directa a la enajenación y propone una lectura de la historia del pensamiento filosófico latinoamericano en la necesaria contraposición entre humanismo $y$ enajenación:

El humanismo constituye precisamente la antítesis de la alienación, pues presupone una reflexión y la praxis que se deriva de ella, dirigida a engrandecer la actividad humana, a hacerla cualitativamente superior en tanto contribuya a que el hombre domine mejor sus condiciones de existencia y se haga más culto. (pp. 87-88)

Ahora bien, para Guadarrama la superación de algunas formas históricas de enajenación no impide que surjan del mismo modo otras nuevas que, a su vez, deberán ser superadas (p. 111). Así, pues, es consciente de la necesaria contextualización de su crítica y del contenido de la misma en función de unas condiciones históricas específicas, de manera que en virtud de tal contextualización debería ser entendida la periodización a la que se ha hecho referencia con anterioridad, propuesta por Carlos Beorlegui, al tratar la obra de Guadarrama.

Una cosa queda clara, y es que la obra de Guadarrama, sin lugar a duda, se inscribe en la relación dialéctica entre humanismo y alienación, en frente a cuyo par relacional tributa precisamente al valor de lo humano como bien supremo en función de contrarrestar la segunda de estas categorías, apelando a lo propio como valor emancipatorio, es decir, a lo auténtico en tanto respuesta desde lo concreto en correspondencia con el momento histórico.

Desde esta tesitura puede entenderse entonces el porqué de su dedicación a temas de investigación ejecutados a lo largo de su vida tales como "Humanismo práctico y desalienación en José Martí" (1990); "La alienación en la modernidad" (1992); "Humanismo y desaliena- 
ción en el pensamiento amerindio" (1994); "Humanismo y alienación en Feuerbach y Marx" (1997); "Humanismo y alienación en la modernidad y la posmodernidad" (1997). Y de esos textos resultaron, además, otros libros como Filosofía, bumanismo y alienación (2001); Humanismo, alienación y globalización (2003); y Pensamiento filosófico latinoamericano: Humanismo vs. Alienación (2008).

La última de tales obras referidas pudiera, incluso, ser considerada como la obra síntesis del aporte de toda una vida dedicada al estudio del pensamiento filosófico latinoamericano, en la cual se apuesta de modo claro por la presentación crítica de la historia del pensamiento en esta región del planeta en términos de contraposición entre las dos categorías anunciadas en el propio título de la obra. Es con seguridad la obra resumen del aporte teórico y de la perspectiva por la que Guadarrama ha apostado a lo largo de toda su vida intelectual.

\section{A modo de epílogo}

Hasta aquí han sido esbozadas algunas de las particularidades más significativas de la obra de Guadarrama, en la cual hemos aludido tanto a la persona como al pensador. Se ha dado fe de su proximidad emblemática como investigador y pedagogo, y se ha dado cuenta del impacto de la obra de toda una vida, de su apuesta por el rescate, reivindicación y cultivo del pensamiento latinoamericano, de su humanismo en perspectiva marxista y de algunas claves vistas en función del lugar de la crítica como herramienta irrenunciable, del lugar de la autenticidad, la originalidad, lo específico y lo universal en su análisis. Así, se ha advertido sobre el valor de lo propio en su apuesta emancipatoria en el marco de una perspectiva que conjuga la rica herencia humanista latinoamericana y la tradición marxista, de las cuales Guadarrama proviene y a las cuales tributa de modo significativo con el sello de lo propio y desde la latinoamericanidad más comprometida. Una apuesta emancipatoria por el humanismo como contraparte a la enajenación, y desde la cual puede leerse tanto la historia del pensamiento latinoamericano como la obra misma de Guadarrama.

Si bien el ser humano, tal y como apuntase Enrique José Varona (1905), no puede sustraerse a cierto determinismo, sí que "puede en cierto modo educarlo y guiarlo que es aquí vencerlo". Unido a lo cual el pensador camagüeyano apuntaría que el ser humano no es un autómata, "más para no serlo se necesita cultivar tanto la inteligencia como el sentimiento" y para ello "la educación es su verdadera reden- 
tora" (p. 410). Y ha sido precisamente la educación, tanto a través de la publicación de su intensa labor investigativa, la coordinación de trabajo de investigación colectiva y la praxis pedagógica propiamente dicha, la vía redentora por la que ha apostado Guadarrama a lo largo de toda una vida. Tanto su labor investigativa como su labor docente escenifican su convencida apuesta por el humanismo y el rescate y significativo aporte al valor emancipatorio de lo propio en el pensamiento latinoamericano.

Si bien los pueblos son los que labran su propio destino, como apunta Varona (1933, p. 131), somos los individuos los responsables de contribuir en ese labrar de la historia, y somos, en nuestro rol de discípulos en esta vida terrena, los encargados de dar continuidad a ese "sembrar ideas" al que el apóstol cubano José Martí hiciera referencia. Discípulos, en efecto, de una rica tradición en la que el pensador villaclareño se inscribe. Y así, como Gaspar Jorge García Galló vislumbró en Guadarrama González su relevo generacional y la garantía de continuidad del estudio del pensamiento latinoamericano y de la investigación filosófica desde una perspectiva crítica, desde lo propio, y comprometida con los de abajo; también hoy el homenajeado profesor puede tener la absoluta convicción de que gracias a su legado de toda una vida, tanto investigativo como pedagógico, su continuidad está, por nuestra parte, asumida. El propio estudio que aquí se presenta es una evidencia de ello. A ello vamos. Y ha de ser este, sin lugar a duda, el mayor de los homenajes posibles para un maestro. Gracias, ¡maestro! Y podemos entonces, más que desiderátum, con todo el compromiso y respeto que ello implica, hacer nuestra aquella expresión del viejo García Galló: ¡Está asegurado el relevo! Las presentes y futuras generaciones de pensadores y estudiosos del pensamiento latinoamericano, conscientes de nuestro lugar en la historia, tenemos en su obra una apuesta decidida por la legítima reivindicación de lo propio como valor emancipatorio.

\section{Referencias}

Beorlegui, C. (2004). Historia del Pensamiento filosófico latinoamericano. Una búsqueda incesante de la identidad. Bilbao: Universidad de Deusto.

Craig, E. (Ed.). (1998). Routledge Encyclopedia of Philosophy. Nueva York: Routledge. 
Dussel, E. (2003). Philosophy in Latin America in the Twentieth Century: Problems and Currents. En E. Mendieta (Ed.), Latin American philosophy: currents, issues, debates. Bloomington: Indiana University Press.

Cueva, A. (1974). Sobre la filosofía y el método marxista. Revista Mexicana de Ciencia Política, (78).

Feijóo, S. (2007). El Pensador Silvestre. La Habana: Editorial Letras Cubanas.

Gracia, J. (1988). Repertorio de filósofos latinoamericanos. Buffalo: Council on International Studies and Programs - State University of New York at Buffalo.

Gracia, J.; Rabossi, E.; Villanueva, E. y Dascal, M (1985). El análisis filosófico en América Latina. México D.F.: Fondo de Cultura Económica.

Gerstenberg, B. Die Philosophie in Kuba und Lateinamerika. Deutsche Zeitschrift fur Philosophie, 35(10), 964-966.

Guadarrama, P. y Pereliguin, N. (1988). Lo universal y lo especifico en la cultura. Bogotá: Universidad INCCA.

Guadarrama, P. (1985). Valoraciones sobre el pensamiento cubano y latinoamericano. La Habana: Editora Política.

Guadarrama, P. (1989). Hay crisis entre los marxistas latinoamericanos, Islas, (92).

Guadarrama, P. (1990). Marxismo y antimarxismo en América Latina. Bogotá: Universidad INCCA de Colombia.

Guadarrama, P. (1993). Humanismo y filosofía de la liberación en América Latina. Bogotá: Editorial El Búho.

Guadarrama, P. (1994). América Latina: Marxismo y postmodernidad. Santa Clara: UCLV; Bogotá: INCCA.

Guadarrama, P. (1997). ¿Qué historia de la filosofía se necesita en América Latina? Islas, (115), 90-106.

Guadarrama, P. (1998). ¿Para qué filosofar? (Funciones de la filosofía). Revista de filosofía, (30), 109-139.

Guadarrama, P. (1999). Despojados de todo fetiche. La autenticidad del pensamiento marxista en América latina. Bogotá: Universidad INCCA de Colombia.

Guadarrama, P. (2001). Humanismo y autenticidad en el pensamiento filosófico latinoamericano. Islas, (128), 87-122.

Guadarrama, P. (2003). José Martí y el bumanismo en América Latina. Bogotá: Convenio Andrés Bello. 
Guadarrama, P. (2004). Positivismo y antipositivismo en América Latina. La Habana: Instituto Cubano del Libro - Editorial de Ciencias Sociales.

Guadarrama, P. (2008). Pensamiento filosófico latinoamericano: bumanismo vs. alienación. Caracas: Editorial el perro y la rana.

Jardines, A. (2004). Rescate de la filosofía republicana. Encuentro de la Cultura Cubana, (34-35), 89-102.

Moncayo, V. (1983). Marx sin marxismo. En In Memorian Marx 18831983 (p. 25). Bogotá: CINEP.

Ribas, P. (2012). Pensamiento filosófico latinoamericano: humanismo vs. alienación. Guadarrama González. Revista de Hispanismo Filosófico, (17), 241.

Roig, A. (2002). Ética del poder y moralidad de la protesta: respuestas a la crisis moral de nuestro tiempo. Mendoza: EDIUNC.

Rojas, C. (2009). El pensamiento ffilosófico del Caribe. En E. Dussel, et. al. (Eds.), El Pensamiento filosófico latinoamericano, del Caribe y latino. México: Siglo XXI - Centro de Cooperación Regional para la Educación de Adultos en América Latina y el Caribe.

Rojas, R. (2008). Souvenirs de un Caribe soviético. Revista Encuentro de la Cultura Cubana, (48-49), 18-33.

Ubieta, E. (2003). Prólogo. En P. Guadarrama, José Martí y el Humanismo en América Latina (p. 12). Bogotá: Convenio Andrés Bello.

Valeri, A, y Cruz, A. (1988) Guadarrama. Valoraciones sobre el pensamiento filosófico cubano y latinoamericano. América Latina, (1).

Varona, E. (1905). Curso de psicología. La Habana: Imprenta La moderna poesía.

Varona, E.J. (1918). Por Cuba. La Habana: Imprenta siglo XX.

Varona, E. (1933). El imperialismo a la luz de la sociología. La Habana: Editorial APRA.

Vitier, M. (Ed.). (1949). Enrique José Varona su pensamiento representativo. La Habana: Editorial Lex.

Zea, L. (30 de noviembre de 2003). El humanismo de Guadarrama. Excelsior, p. 2. 